\title{
IGFBP-4 expression is adversely associated with lung cancer prognosis
}

\author{
YANG XIAO*, SHAN ZHU*, WEN YIN, XIAOFAN LIU and YI HU \\ Department of Respiratory Medicine, Central Hospital of Wuhan, Wuhan, Hubei 430014, P.R. China
}

Received November 9, 2015; Accepted April 21, 2017

DOI: 10.3892/ol.2017.7014

\begin{abstract}
Insulin-like growth factor binding protein-4 (IGFBP-4) was reported to be associated with prognosis in several types of cancer; however, to the best of our knowledge, whether it is correlated with lung cancer has yet to be reported. In the present study, 102 pairs of lung cancer tissues and surrounding non-cancerous tissues (SNCTs) were collected. The IGFBP-4 levels in tissues were detected with immunohistochemistry. The relevance of IGFBP-4 to the survival of patients was assessed. The IGFBP-4 gene was knocked down, and its function in the proliferation of lung cancer cells was measured. The percentage of lung cancer tissues with higher IGFBP-4 expression than SNCTs (51.9\%) was increased compared with the percentage with similar $(11.76 \%)$ or lower (36.27\%) IGFBP-4 expression. Patients with higher IGFBP-1 expression exhibited a shorter median survival time. IGFBP-1 was associated with metastasis, lung cancer stages and malignancy, but not with age, sex or tumor size. Lung cancer cells with stably knocked down IGFBP-4 showed an inhibitory proliferation rate. The present study identified that IGFBP-4 was adversely associated with the prognosis of lung cancer patients. IGFBP-4 knockdown prohibited lung cancer cell growth. The present study provides a potential marker for lung cancer diagnosis and a possible target for lung cancer therapy.
\end{abstract}

\section{Introduction}

Lung cancer is a malignant tumor that originates from lung tissues with uncontrolled cell growth. Lung cancer is the leading cause of cancer-associated death worldwide (1). This led to 1.56 million mortalities in 2012 (2). Lung cancer is mainly composed of two types of cancer, consisting of small cell lung cancer (SCLC) and non-small cell lung cancer (NSCLC). The majority of lung cancer cases are induced by

Correspondence to: $\mathrm{Dr} \mathrm{Yi} \mathrm{Hu}$, Department of Respiratory Medicine, Central Hospital of Wuhan, 26 Shengli Road, Wuhan, Hubei 430014, P.R. China

E-mail: tians_li@sina.com

*Contributed equally

Key words: IGFBP-4, lung cancer, prognosis, proliferation, therapy long-term exposure to tobacco. The symptoms of lung cancer are mostly severe coughing, chest pain and weight loss. The current therapeutic methods for lung cancer are primarily surgery, chemotherapy and radiotherapy (3). Treatment and outcome depends on the cancer type and the health status of the individual (3). Although there are several types of therapeutic approaches for lung cancer, the efficacy of the treatments remains unsatisfactory. Investigating a novel target for lung cancer therapy is of critical importance.

Insulin-like growth factor binding protein-4 (IGFBP-4) is a member of the IGBP family of proteins. It consists of an IGF binding domain and a thyroglobulin type-I domain (4). IGFBP-4 binds both IGF I and IGF II. Binding of these ligands prolongs the half-life of IGFs and extends their function. IGFBP-4 alters the interactions between IGF ligands and cell surface receptors, which in turn promotes cell proliferation (5). IGFBP-4 expression is correlated with several types of cancers (6-8). In 2009, Gupta et al (9) found an effective anti-cancer stem cell small molecule, salinomycin, through high-throughput screening of cancer stem cells. Salinomycin strongly inhibited breast cancer stem cells and downregulated (LRP6, survivin and histone H3 and H4) or upregulated (p21) several genes $(10,11)$. It was found that IGFBP-4 gene expression was downregulated by salinomycin treatment (9). As IGFBP-4 is a cancer cell growth-associated gene that has, to the best of our knowledge, never been reported in lung cancer, the present study investigated whether the gene is associated with the prognosis of patients with lung cancer.

\section{Materials and methods}

Tumor sample collection. In total, 102 patients were selected between January 2014 and May 2016. All tissues were collected with informed consent. The majority (90 out of 102) of lung cancer patients did not have metastasis. Overall, $52.0 \%$ $(53 / 102)$ of the patients were female and $48.0 \%$ (49/102) were male. Patients at late stage or early stages were all included. All experiments were approved by the Institutional Review Board of Central Hospital of Wuhan (Wuhan, China).

Immunohistochemistry. All tissues were selected by an experienced pathologist and embedded in paraffin. The immunohistochemistry assay was performed following standard protocols $(12,13)$. Briefly, all the embedded tissues were cut into $3-\mu \mathrm{m}$ slices. The slices were deparaffinized with xylene and 
graded ethanol. The tissues were treated with $0.3 \%$ hydrogen peroxidase, incubated with a primary rabbit anti-IGFBP-4 antibody (dilution, 1:100; cat. no. ab4253; Abcam, Cambridge, UK) overnight at $4^{\circ} \mathrm{C}$ followed by incubation with anti-rabbit IgG-horseradish peroxidase (HRP) secondary antibody (dilution, 1:1,000; cat. no. MBS435036; MyBioSource, San Diego, CA, USA) at room temperature for $1 \mathrm{~h}$. The tissues were washed three times with PBS between antibody incubations. The tissues were observed under microscopes (BX4; Olympus Corporation, Tokyo, Japan; magnification, x40) and the expression levels of IGFBP-4 were considered to be extremely strong, strong, median, weak and none according to the density of signals.

Cell culture. The lung cancer A549 and lentivirus packaging 293T cell lines were purchased from Cell Bank of Chinese Academy of Sciences (Shanghai, China). The cells were maintained in Dulbecco's modified Eagle's medium (DMEM, Thermo Fisher Scientific, Waltham, MA, USA) supplemented with $10 \%$ fetal bovine serum (FBS, Sigma-Aldrich; Merck $\mathrm{KGaA}$, Darmstadt, Germany) and passaged at 1:3 when cells had reached confluence. The cells were incubated in humid atmosphere at $37^{\circ} \mathrm{C}$ with $5 \% \mathrm{CO}_{2}$.

Short hairpin (sh)RNA construction. The shRNA construct to target IGFBP-4 was cloned into lentivirus plasmid pLKO1 (Addgene, Inc., Cambridge, MA, USA). The targeting sequence of IGFBP-4 was 5'-GCCACTTGCGCCCTGGGCTTG-3'. The oligo 1 (5'-AATTCGCCACTTGCGCCCTGGGCTTGATGC CAAGCCCAGGGCGCAAGTGGCG-3') and oligo 2 (5'-AAT TCGCCACTTGCGCCCTGGGCTTGCATCAAGCCCAGG GCGCAAGTGGCGG-3') sequences were diluted to $100 \mu \mathrm{M}$ for annealing. They were mixed together with T4 DNA ligase buffer, heated at $95^{\circ} \mathrm{C}$ for $10 \mathrm{~min}$ and cooled slowly at a rate of $1^{\circ} \mathrm{C} / \mathrm{min}$. The pLKO1 plasmid was cut using the EcoRI restriction enzyme and ligated using annealed oligos to generate the pLKO-IGFBP-4 shRNA-1 plasmid. Another IGFBP-4 shRNA was generated using the same method and its targeting sequence was 5'-GACAAGGACGAGGGTGACCA-3'.

Lentivirus package and stable cell lines. pLKO-IGFBP-4 shRNA-1 and pLKO-IGFBP-4 shRNA-2 were co-transfected with vesicular stomatitis virus- $\mathrm{G}$ and delta 8.2 (Addgene, Inc.) into $293 \mathrm{~T}$ cells to package lentivirus. The medium was changed $12 \mathrm{~h}$ post-transfection. The $293 \mathrm{~T}$ medium was collected 48 , 72 and $96 \mathrm{~h}$ post transfection. The media were centrifuged at $8,000 \mathrm{x} \mathrm{g}$ for $20 \mathrm{~min}$ to remove the cell debris. The medium contained the lenti-IGFBP-4 shRNA-1 or lenti-IGFBP-4 shRNA-2 viruses. The A549 cells were infected with viruses and selected with $2 \mu \mathrm{g} / \mathrm{ml}$ puromycin $48 \mathrm{~h}$ later. The stable cell lines were passaged and maintained in DMEM 10\% FBS with $2 \mu \mathrm{g} / \mathrm{ml}$ puromycin.

Reverse transcription-quantitative polymerase chain reaction (RT-qPCR). RNA was extracted from A549 cells and A549 cells stably transfected with IGFBP-4 shRNA-1 and IGFBP-4 shRNA-2 with TRIzol (Invitrogen; Thermo Fisher Scientific, Inc., Waltham, MA, USA), according to the manufacturer's protocol. In total, $1 \mu \mathrm{g}$ RNA was reverse transcribed into cDNA by Superscript II Reverse Transcription kit (Invitrogen;
Thermo Fisher Scientific, Inc.). The RT-qPCR were performed with SYBR-Green master mix (Thermo Fisher Scientific, Inc.), as follows: Preheating at $94^{\circ} \mathrm{C}$ for $5 \mathrm{~min}$, then 40 cycles of $94^{\circ} \mathrm{C}$ denaturation for $30 \mathrm{sec}, 55^{\circ} \mathrm{C}$ annealing for $30 \mathrm{sec}$ and $72^{\circ} \mathrm{C}$ elongation and data collection for $1 \mathrm{~min}$. The primers for IGFBP-4 were as follows: Forward, 5'-AGGGTGACCACC CCAACAAC-3'; and reverse, 5'-TCCAGCGCCCGGTGC AGCTC-3'. The primers for the internal control gene GAPDH were as follows: Forward, 5'-GCGAGATCCCTCCAAAAT CAA-3'; and reverse 5'-GTTCACACCCATGACGAACAT-3'. $\mathrm{Cq}$ values were processed using $2^{-\Delta \Delta \mathrm{Cq}}$ method to calculate the relative expression level (14).

Western blot analysis. Total protein was extracted from A549 cells, A549 IGFBP-4 shRNA-1 cells and A549 IGFBP-4 shRNA-2 cells using NP40 lysis buffer containing protease inhibitors and phosphatase inhibitors cocktail (Thermo Fisher Scientific, Inc.). The protein concentration was measured with bicinchoninic acid assay (Bio-Rad Laboratories, Inc., Hercules, CA, USA). Denatured protein $(40 \mu \mathrm{g})$ was loaded and separated $10 \%$ SDS-PAGE. The proteins were transferred onto polyvinylidene fluoride membranes (Merck KGaA, Darmstadt, Germany), blocked with 5\% non-fat milk, primary rabbit anti-IGFBP-4 antibody (dilution, 1:100; cat. no. ab4253; Abcam) and anti-rabbit IgG-HRP secondary antibody (dilution, 1:1,000; cat. no. MBS435036; MyBioSource). The membranes were exposed to the film for band development. GAPDH blotted by primary rabbit anti-IGFBP-4 antibody (dilution, 1:100; cat. no. ab8245; Abcam). GAPDH (Cell Signaling Technology, Inc., Danvers, MA, USA) was used as an endogenous control in this assay.

Cell proliferation detection. The A549 cells, A549 IGFBP-4 shRNA-1 cells and A549 IGFBP-4 shRNA-2 cells were plated onto 96-well dishes at 2,000 cells per well. The cell viability was measured using an MTT assay (Thermo Fisher Scientific, Inc.) at the indicated days, according to the manufacturer's protocol.

Online database. The Kaplan-Meier Plotter online database (8) was used to analyze the association between IGFBP-4 and lung cancer.

Statistical analysis. The data were expressed as the mean + standard deviation $(\mathrm{SD})$ or mean \pm SD. The differences between groups were analyzed by one-way analysis of variance and least significant difference analysis. The survival curve was generated using the Kaplan-Meier method. The median survival comparison between groups was calculated using the log-rank test. $\mathrm{P}<0.05$ was considered to indicate a statistically significant difference.

\section{Results}

Lung cancer tissues expressed increased levels of IGFBP-4. To assess the expression level of IGFBP-4 in lung cancer tissues and SNCTs, the tissues were stained with IGFBP-4 by immunohistochemistry. Lung cancer tissues showed increased IGFBP-4 expression compared with SNCT (Fig. 1). In 53 of the 102 paired tissues, cancer tissues expressed an increased 
Table I. Association between IGFBP-4 expression and pathological parameters in lung cancer tissue specimens.

\begin{tabular}{|c|c|c|c|}
\hline \multirow[b]{2}{*}{ Parameter } & \multicolumn{2}{|c|}{$\begin{array}{c}\text { IGFBP-4 } \\
\text { expression, } n\end{array}$} & \multirow[b]{2}{*}{ P-value } \\
\hline & Low & High & \\
\hline Age & & & 0.388 \\
\hline$\geq 60$ years & 21 & 31 & \\
\hline$<60$ years & 21 & 29 & \\
\hline Sex & & & 0.286 \\
\hline Male & 19 & 30 & \\
\hline Female & 23 & 30 & \\
\hline Metastasis & & & 0.016 \\
\hline Yes & 1 & 5 & \\
\hline No & 41 & 55 & \\
\hline TNM stage & & & 0.038 \\
\hline I-II & 21 & 26 & \\
\hline III-IV & 10 & 38 & \\
\hline Malignance & & & 0.043 \\
\hline High & 20 & 18 & \\
\hline Low & 22 & 42 & \\
\hline Tumor size & & & 0.216 \\
\hline Big & 25 & 32 & \\
\hline Small & 18 & 27 & \\
\hline
\end{tabular}

IGFBP-4, insulin-like growth factor binding protein-4; TNM, tumor-node-metastasis.

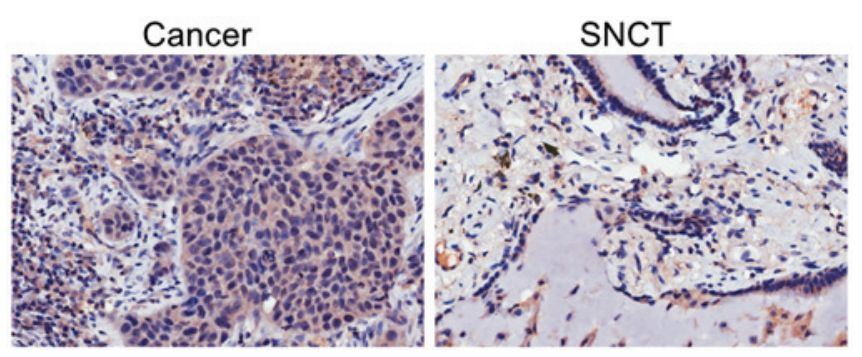

Figure 1. Lung cancer tissues expressed an increased level of insulin-like growth factor binding protein-4. Cancer, lung cancer tissues; SNCT, surrounding non-cancerous tissues (magnification, $\mathrm{x} 40$ ).

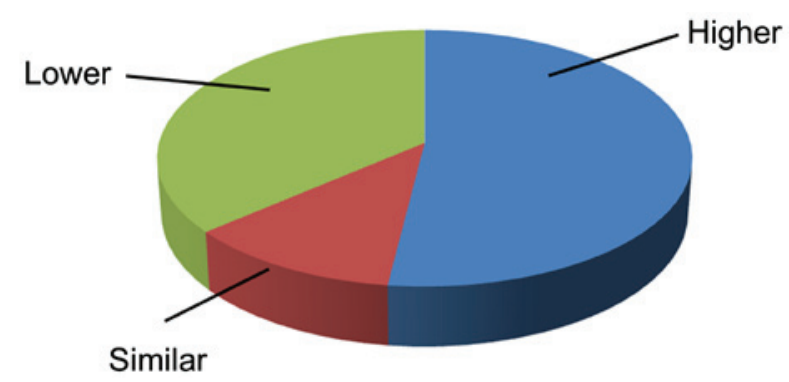

Figure 2. Comparison of expression level of IGFBP-4 between lung cancer tissue and surrounding tissues The pie demonstrates that lung cancer tissue from $\sim 52 \%$ of patients showed a higher expression level of IGFBP-4 compared with surrounding non-cancerous tissues, and $\sim 12 \%$ was similar and $36 \%$ was lower. IGFBP-4, insulin-like growth factor binding protein-4.

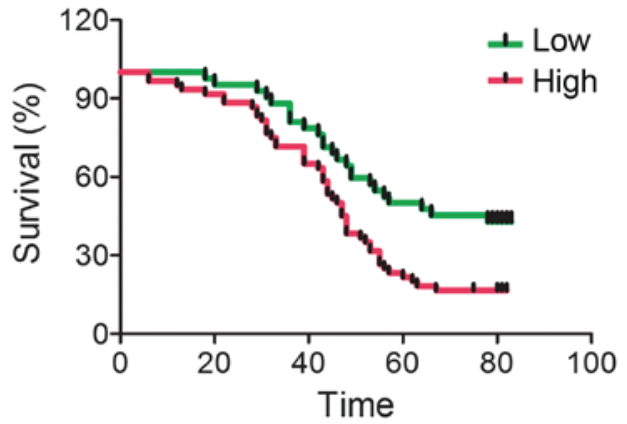

Figure 3. IGFBP-4 expression was adversely associated with lung cancer prognosis. The association between IGFBP-4 expression and survival rate (\%) were analyzed. IGFBP-4, insulin-like growth factor binding protein-4.
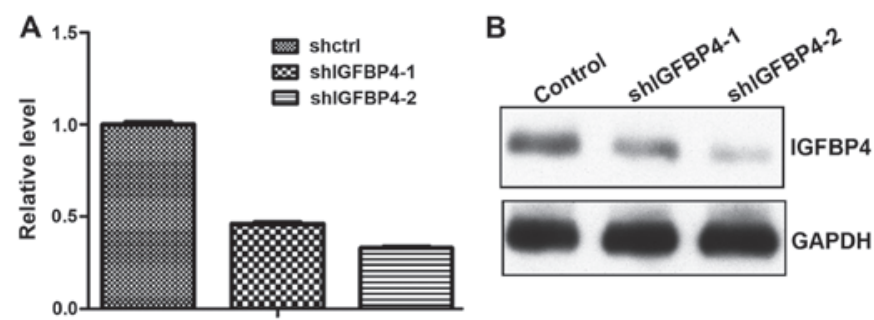

Figure 4. IGFBP-4 was efficiently knocked down in lung cancer cells (A) IGFBP-4 mRNA detection in A549 cells and IGFBP-4-knockdown cells. (B) IGFBP-4 expression in A549 cells and IGFBP-4-knockdown cells was detected at the protein level. IGFBP-4, insulin-like growth factor binding protein-4; shctrl, control short hairpin RNA; shIGFBP4-1, pLKO-IGFBP-4 short hairpin RNA-1; shIGFBP4-2, pLKO-IGFBP-4 short hairpin RNA-2.

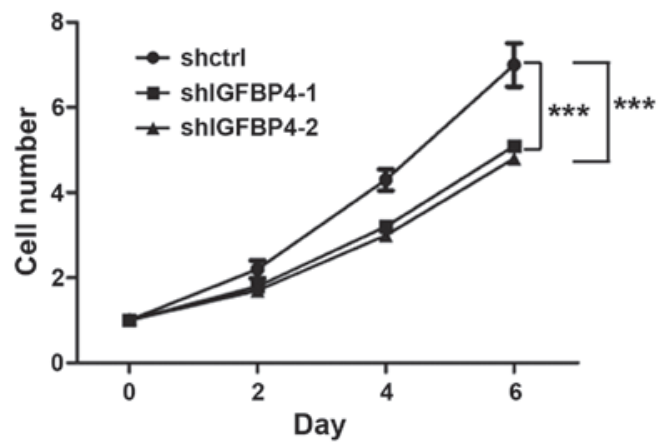

Figure 5. IGFBP-4 knockdown inhibited lung cancer cell growth. Cell viability of A549 and A549 IGFBP-4-knockdown cells were measured at the indicated days. ${ }^{* * *} \mathrm{P}<0.001$. IGFBP-4, insulin-like growth factor binding protein-4; shctrl, control short hairpin RNA; shIGFBP4-1, pLKO-IGFBP-4 short hairpin RNA-1; shIGFBP4-2, pLKO-IGFBP-4 short hairpin RNA-2.

level of IGFBP-4 compared with SNCTs. This percentage $(51.96 \%)$ is larger than the proportion of patients with similar $(11.76 \%)$ or decreased $(36.27 \%)$ levels of IGFBP-4 expression in cancer tissues (Fig. 2).

IGFBP-4 is adversely associated with lung cancer prognosis. To investigate whether IGFBP-4 expression is associated with lung cancer prognosis, the present study compared IGFBP-4 expression with the survival of lung cancer patients. It was shown that patients with increased IGFBP-4 expression have a shorter median survival rate (Fig. 3). It was also found that IGFBP-4 expression was associated with metastasis, TNM 
stages and tumor malignancy, but not with age, sex or tumor size (Table I).

IGFBP-4 knockdown promoted lung cancer cell growth. To assess whether blocking the function of IGFBP-4 could inhibit lung cancer progression, the present study knocked down IGFBP-4 expression by shRNAs. Lentivirus-mediated shRNA sufficiently knocked down IGFBP-4 expression at the mRNA (Fig. 4A) and protein level (Fig. 4B). With IGFBP-4 knockdown, A549 cells showed a slower proliferation rate (Fig. 5). This indicated that IGFBP-4 promoted lung cancer cell proliferation.

\section{Discussion}

IGFBP-4 is an IGF binding protein that may affect the half-life of IGFs and promote or inhibit tumor growth. It was reported in inhibiting colon cancer growth $(7,15)$. In 2009, researchers at the Massachusetts Institute of Technology investigated an effective drug for the targeting of breast cancer stem cells. Salinomycin was found to markedly inhibit breast cancer stem cells. This study compared the effect of salinomycin and the chemotherapy drug Paclitaxel on cancer stem cells. Salinomycin could markedly inhibit cancer stem cell properties (9). Salinomycin has been evaluated by several studies in various types of cancer stem cells (16-20). Salinomycin downregulated the expression of IGFBP-4 and certain other genes compared with Paclitaxel treatment. Breast cancer spheres, namely cancer stem cells, had IGFBP-4 expression that was $\sim 3$ folds higher than the expression in adherent cells $(9,21)$. This suggested that IGFBP-4 may be relevant to cancer stem cells. As cancer stem cells are the most important subpopulation in various types of cancers, IGFBP-4 may promote cancer progression.

Lung cancer, which is the most common cancer in the world, causes 2 million cancer-associated mortalities worldwide every year (1). Developing an effective therapeutic method for lung cancer therapy is of marked importance. To identify whether lung cancer is associated with IGFBP-4 expression, the Kaplan-Meier Plotter database (22) was used to analyze the association. Patients with increased IGFBP-4 expression had a decreased survival rate. IGFBP-4 was adversely associated with lung cancer progression. This online analysis result is consistent with the present hypothesis. In the current study, 102 pairs of cancer tissues and surrounding non-cancerous tissues were collected. The expression of IGFBP-4 was detected by immunohistochemistry in these tissues. It was found that IGFBP-4 is highly expressed in lung cancer tissues (Figs. 1 and 2). Patients with increased IGFBP-4 expression in cancer tissues showed a decreased median survival time (Fig. 3).

To identify whether IGFBP-4 expression affects lung cancer progression, its function in the lung cancer A549 cell line was detected in vitro. The expression of IGFBP-4 was identified in several different cancer cell lines using the The Human Protein Atlas $(23,24)$. Lung cancer cell lines were found to highly express IGFBP-4. The A549 cells particularly expressed a high level of IGFBP-4. IGFBP-4 was knocked down in A549 cells and the expression was markedly decreased at the mRNA and protein levels (Fig. 4). The effect of the knockdown effect on cell proliferation was detected, and it was found that IGFBP-4 knockdown could inhibit the proliferation of A549 cells (Fig. 5).

In the present study, IGFBP-4 was associated with lung cancer prognosis. Knockdown of IGFBP-4 leads to the inhibition of proliferation in lung cancer cells. As IGFBP-4 is associated with breast cancer stem cells, it was likely to also be associated with lung cancer stem cells. Targeting IGFBP-4 may lead to the inhibition of lung cancer stem cell growth. As lung cancer stem cells are associated with chemoresistance, progression and metastasis of lung cancer (25-27), this may lead to the long-term inhibition of lung cancer development. This may be investigated in a future study. In conclusion, the current study identified the adverse association between IGFBP-4 and lung cancer prognosis. This provides a potential target for lung cancer therapy.

\section{References}

1. Torre LA, Bray F, Siegel RL, Ferlay J, Lortet-Tieulent J and Jemal A: Global cancer statistics, 2012. CA Cancer J Clin 65: 87-108, 2015.

2. Rabasseda X: A report from the world conference on lung cancer (September 6-9, 2015-Denver, Colorado, USA). Drugs Today (Barc) 51: 559-567, 2015.

3. Siegel RL, Miller KD and Jemal A: Cancer statistics, 2015. CA Cancer J Clin 65: 5-29, 2015.

4. Shimasaki S, Shimonaka M, Zhang HP and Ling N: Identification of five different insulin-like growth factor binding proteins (IGFBPs) from adult rat serum and molecular cloning of a novel IGFBP-5 in rat and human. J Biol Chem 266: 10646-10653, 1991.

5. Mohan S, Nakao Y, Honda Y, Landale E, Leser U, Dony C, Lang K and Baylink DJ: Studies on the mechanisms by which insulin-like growth factor (IGF) binding protein-4 (IGFBP-4) and IGFBP-5 modulate IGF actions in bone cells. J Biol Chem 270: 20424-20431, 1995.

6. Mosig RA, Lobl M, Senturk E, Shah H, Cohen S, Chudin E, Fruscio R, Marchini S, D'Incalci M, Sachidanandam R, et al: IGFBP-4 is a candidate serum biomarker for detection and surveillance of early stage epithelial ovarian cancer. Research 2 : $1342,2015$.

7. Mosig RA, Lobl M, Senturk E, Shah H, Cohen S, Chudin E, Fruscio R, Marchini S, D'Incalci M, Sachidanandam R, et al: IGFBP-4 tumor and serum levels are increased across all stages of epithelial ovarian cancer. J Ovarian Res 5: 3, 2012.

8. Drivdahl RH, Sprenger C, Trimm K and Plymate SR: Inhibition of growth and increased expression of insulin-like growth factor-binding protein-3 (IGFBP-3) and-6 in prostate cancer cells stably transfected with antisense IGFBP-4 complementary deoxyribonucleic acid. Endocrinology 142: 1990-1998, 2001.

9. Gupta PB, Onder TT, Jiang G, Tao K, Kuperwasser C, Weinberg RA and Lander ES: Identification of selective inhibitors of cancer stem cells by high-throughput screening. Cell 138: 645-659, 2009.

10. Lu W and Li Y: Salinomycin suppresses LRP6 expression and inhibits both Wnt/ $\beta$-catenin and mTORC1 signaling in breast and prostate cancer cells. J Cell Biochem 115: 1799-1807, 2014.

11. Al Dhaheri Y, Attoub S, Arafat K, Abuqamar S, Eid A, Al Faresi N and Iratni R: Salinomycin induces apoptosis and senescence in breast cancer: Upregulation of p21, downregulation of survivin and histone $\mathrm{H} 3$ and $\mathrm{H} 4$ hyperacetylation. Biochim Biophys Acta 1830: 3121-3135, 2013.

12. Fitzgibbons PL, Bradley LA, Fatheree LA, Alsabeh R, Fulton RS, Goldsmith JD, Haas TS, Karabakhtsian RG, Loykasek PA, Marolt MJ, et al: Principles of analytic validation of immunohistochemical assays: Guideline from the College of American Pathologists Pathology and Laboratory Quality Center. Arch Pathol Lab Med 138: 1432-1443, 2014.

13. Mellors RC: The application of labeled antibody technics in studying cell antigens. Cancer Res 28: 1372-1381, 1968.

14. Livak KJ and Schmittgen TD: Analysis of relative gene expression data using real-time quantitative PCR and the 2(-Delta Delta C(T)) method. Methods 25: 402-408, 2001. 
15. Durai R, Davies M, Yang W, Yang SY, Seifalian A, Goldspink G and Winslet M: Biology of insulin-like growth factor binding protein-4 and its role in cancer (review). Int J Oncol 28: 1317-1325, 2006.

16. Diehl D, Lahm H, Wolf E and Bauersachs S: Transcriptome analysis of a human colorectal cancer cell line shows molecular targets of insulin-like growth factor-binding protein-4 overexpression. Int J Cancer 113: 588-599, 2005.

17. Resham K, Patel PN, Thummuri D, Guntuku L, Shah V, Bambal RB and Naidu VG: Preclinical drug metabolism and pharmacokinetics of salinomycin, a potential candidate for targeting human cancer stem cells. Chem Biol Interact 240: $146-152,2015$

18. Kopp F, Hermawan A, Oak PS, Herrmann A, Wagner E and Roidl A: Salinomycin treatment reduces metastatic tumor burden by hampering cancer cell migration. Mol Cancer 13: 16, 2014.

19. Naujokat $C$ and Steinhart R: Salinomycin as a drug for targeting human cancer stem cells. J Biomed Biotechnol 2012: 950658, 2012.

20. Tang QL, Zhao ZQ, Li JC, Liang Y, Yin JQ, Zou CY, Xie XB, Zeng YX, Shen JN, Kang T and Wang J: Salinomycin inhibits osteosarcoma by targeting its tumor stem cells. Cancer Lett 311: 113-121, 2011.
21. Patel N, Baranwal S and Patel BB: A strategic approach to identification of selective inhibitors of cancer stem cells. Methods Mol Biol 1229: 529-541, 2015.

22. Győrffy B, Surowiak P, Budczies J and Lánczky A: Online survival analysis software to assess the prognostic value of biomarkers using transcriptomic data in non-small-cell lung cancer. PLoS One 8: e82241, 2013.

23. Uhlen M, Fagerberg L, Hallström BM, Lindskog C, Oksvold P, Mardinoglu A, Sivertsson A, Kampf C, Sjöstedt E, Asplund A, et al: Proteomics. Tissue-based map of the human proteome. Science 347: 1260419, 2015.

24. Ponten F, Jirström K and Uhlen M: The human protein Atlas-a tool for pathology. J Pathol 216: 387-393, 2008.

25. Yang Y, Xu H, Huang W, Ding M, Xiao J, Yang D, Li H, Liu XY and Chu L: Targeting lung cancer stem-like cells with TRAIL gene armed oncolytic adenovirus. J Cell Mol Med 19: 915-923, 2015.

26. Chen K, Huang YH and Chen JL: Understanding and targeting cancer stem cells: Therapeutic implications and challenges. Acta Pharmacol Sin 34: 732-740, 2013.

27. Pine SR, Marshall B and Varticovski L: Lung cancer stem cells. Dis Markers 24: 257-266, 2008. 